MicroRNA-dependent Genetic Networks During Neural
Development
Cell Tissue Res. 2015 January ; 359(1): 179-185. doi:10.1007/s00441-014-1899-4.
Daniel G. Abernathy ${ }^{1,2}$ and Andrew S. Yoo'
'Department of Developmental Biology, Washington University School of Medicine, St. Louis,
63110, USA
2Program of Developmental, Regenerative, and Stem Cell Biology, Washington University Schoor
of Medicine, St. Louis, MO 63110, USA
Abstract
The development of the structurally and functionally diverse mammalian nervous system requires
the integration of numerous levels of gene regulation. Accumulating evidence suggests that
microRNAs are key mediators of genetic networks during neural development. Importantly,
microRNAs are found to regulate both feedback and feedforward loops during neural development
leading to large changes in gene expression. These repressive interactions provide an additional
mechanism that facilitates the establishment of complexity within the nervous system. Here, we
review studies that have enabled the identification of brain-enriched microRNAs and discuss how
genetic networks in neural development depend on microRNAs.

\title{
Introduction
}

Development of the mammalian nervous system results from the combinatorial action of morphogenetic gradients, cell-cell signaling, transcriptional networks, and cell migration (Götz and Huttner, 2005). The output of this intricate regulatory network is a collection of interconnected neural cells comprised of glia and neurons. These two cell types can be subdivided further into distinct, highly specialized cells. In addition to developmental programs governed by transcription factors, non-coding RNAs facilitate neural fate acquisition (Cao et al., 2006; Cochella and Hobert, 2012; Pauli et al., 2011; Sun et al., 2013). The most widely characterized are small 20-24 nucleotide long microRNAs (miRNAs) that coordinate gene expression at the post-transcriptional level (Bartel, 2009; Krol et al., 2010; Pasquinelli, 2012) through translational inhibition and mRNA decay (Bartel, 2009; Bazzini et al., 2012; Djuranovic et al., 2012; Pasquinelli, 2012). These short stretches of RNA can have marked effects on gene networks as a single miRNA can target hundreds of mRNAs (Bernstein et al., 2003; Chi et al., 2009; Peter, 2010). Furthermore, multiple miRNAs can target a single transcript, dramatically increasing the effect on single gene expression (Wu et al., 2010). These properties enable miRNAs to act in both feedforward and feedback loops (reviewed in Ebert and Sharp, 2012) in order to establish developmental transitions, cell fate switches, and to refine gene expression. 
miRNAs have been shown to be an integral part of transcriptional networks that drive developmental programs. The importance of miRNAs in many aspects of neural development has been reviewed elsewhere (Cao et al., 2006; Cochella and Hobert, 2012; Pauli et al., 2011; Sun et al., 2013) and in this issue. Here, we discuss studies that have increased our understanding of the activities of miRNAs during neuronal differentiation. We then focus on how genetic programs rely on specific miRNAs to reinforce transcriptional programs during neural development through feedback and feedforward genetic networks. Identification of genetic pathways from neural developmental studies has led to the ability to differentiate neurons from embryonic and induced pluripotent stem cells and recently, reprogram non-neuronal cells into neurons (reviewed in Morris and Daley, 2013), demonstrating the necessity to understand how miRNAs contribute in cell fate decisions during neural development.

\section{miRNAs in Development}

The major path to a mature miRNA begins in the nucleus where RNA polymerase II transcribes a primary miRNA transcript (pri-miRNA) that ranges in length, but is generally around several hundred base pairs (Lee et al., 2002). The pri-miRNA is processed down to a 60-100 nucleotide precursor hairpin (pre-miRNA) by Drosha and its cofactor DGCR8 (Bartel, 2009; Krol et al., 2010; Pasquinelli, 2012). The intermediate pre-miRNAs are transported into the cytoplasm by Exportin 5 where they are cleaved into their mature 19-25 nucleotide form by Dicer. Mature miRNAs are loaded into the RNA induced silencing complex (RISC) that, in complex with Argonaute (Ago) proteins, typically targets the 3'UTR of mRNAs. This leads to either translational repression or mRNA degradation (Bartel, 2009; Bazzini et al., 2012; Djuranovic et al., 2012; Pasquinelli, 2012).!

Initial investigations into the role of miRNAs in development were based on disruption of miRNA biogenesis. With the observation that whole mouse embryo Dicer knockouts die at E7.5, many groups focused on generating tissue-specific Dicer deletion strains using Cre expression (Bernstein et al., 2003). Although the role of specific miRNAs acting through canonical miRNA biogenesis cannot be assessed using this strategy, it has revealed interesting facets of miRNAs in general and their role during neural development. Notably, proper migration, differentiation, and integration of neurons during neurogenesis requires mature miRNAs (Bernstein et al., 2003; Kawase-Koga et al., 2009; Makeyev et al., 2007; Volvert et al., 2012). Deleting Dicer in the telencephalon during neural development using a FoxG1-Cre line resulted in increased apoptosis culminating in a thinner cortical plate (Makeyev et al., 2007). Although there appears to be no effect on differentiation, the stereotyped organization of the cortex is disrupted. Further refining Dicer ablation in the cortex through the use of a Emx1-Cre driver yields analogous results, but cortical defects appear earlier in development (De Pietri Tonelli et al., 2008). Similarly, deleting Dicer in neural progenitors using Nestin-Cre results in increased apoptosis, reduced cortical thickness, and increased ventricular volume (Kawase-Koga et al., 2009).

FoxG1 and Emx1 are restricted rostrally with Emx1 being the most cortical specific, yet in terms of cortical defects, these two Cre-drivers lead to earlier cell death and premature neuronal differentiation when compared to the Nestin-Cre driver. This is surprising since 
Nestin is expressed in all neural progenitors. Kawase-Koga and Sun attribute this difference to the timing of Dicer deletion, as opposed to cell types. Delineating the miRNAs responsible for the myriad of phenotypes observed in Dicer knockouts has previously been technically unfeasible. Now, we are able to examine specific miRNAtarget networks at a global level, which has facilitated the dissection of miRNA-dependent biological processes.

\section{Identification of miRNAs enriched in the nervous system}

Advances in sequencing technology within the past 10 years have greatly increased the detectability of specific miRNAs and their targets within a select population of cells. These techniques have also shifted several commonly accepted notions of miRNA-mediated regulation by demonstrating binding outside the 3'UTR (Lee et al., 2009; Lytle et al., 2007; Ørom et al., 2008), localization of functioning miRNAs in the nucleus (Buckley et al., 2012; Jeffries et al., 2011; Khudayberdiev et al., 2013) and lastly bypassing the requirement of the 5' seed regions (Boudreau et al., 2013; Chi et al., 2012; Helwak et al., 2013). Collectively, these studies reveal a wider network of target genes and further emphasize the importance of miRNAs in gene regulation.

Identifying a collection of miRNAs and their targets has been accomplished primarily through target prediction algorithms, crosslinking techniques such as HITS-CLIP and PARCLIP, Ago-HITS-CLIP, and miRNA microarrays (Chi et al., 2009; Hafner et al., 2010; Liu et al., 2004; Ule et al., 2005). Each of these tools generates hundreds of possible miRNAs and targets that must be further validated. Nonetheless, they have revealed changes in miRNA expression as the brain develops and have identified many targets that mediate developmental transitions and neuronal function, including widely characterized miRNAs, miR-124, miR-9, miR-125, miR-132 and the let-7 families (Cochella and Hobert, 2012). In addition, these techniques can be applied to post-mortem human samples thus enabling the identification and validation miRNAs-mRNA interactions within the human brain (Boudreau et al., 2013), allowing comparisons of miRNA expression and target recognitions in different species.

Boudreau et al. observed a marked difference in the conserved binding sites between mouse and human brains (Boudreau et al., 2013). While the authors note the methods used to collect and determine the mouse data could have caused this difference, others have hypothesized that miRNAs are strong contributors to brain evolution and cognition (Bentwich et al., 2005; Hu et al., 2011; Lukiw, 2012) suggesting that the difference between mouse, primate and human miRNA expression may have biological meanings.

Further refinement of miRNA and target expression analysis through the expression of tagged-Ago proteins has enabled miRNA profiling in specific neuronal subtypes. Given the potent effects miRNAs have on both neurogenesis and neuronal function, determining the cell specific miRNA expression profile within neurons is fundamental to understanding their development (Hobert et al., 2010; Sempere et al., 2004). He et al. characterized the miRNA expression profile of five neuronal subtypes within the brain and revealed that glutamatergic, GABAergic, and subclasses of GABAergic neurons within the neocortex and cerebellum, respectively, contain distinct but overlapping miRNA expression profiles (He et 
al., 2012). For example, parvalbumin (PV) and somatostatin (SST) expressing GABAergic interneurons overlap in miR-124 and miR-9 expression while SST interneurons express miR-187 and miR-551b at a level 6-fold higher than PV interneurons. Similarly, Camk2a neurons in the neocortex express miR-296 and miR-130b significantly more than Gad2 neurons from the same neuronal compartment. It is important to note that over 100 miRNAs were shown to have significant differential expression between sub-type comparisons. Interestingly, the authors also observed cell-type specific miRNA strand selection from precursors within different neuronal subtypes which could provide alternative target selection. So far, the exact role of miRNAs enriched in different neuronal subtypes largely remains unknown.

\section{Function of miRNAs in Early Neural Development}

Once dorsal ectoderm is specified to become neuroectoderm through BMP and activin inhibition and increased Wnt and FGF signaling the central nervous system starts to take shape (Stern, 2005). The appearance of the neural plate and formation of the neural folds dorsal to the neural plate provides the framework for cell specification. Positional information along rostro-caudal and dorso-ventral axis of the neural tube has been shown to demarcate future cell fate largely through the action of ventral Shh, dorsal BMP and rostrocaudal retinoic acid gradients (Jessell, 2000; Stern, 2005). The mechanism that establishes progenitor domains along these axis relies on a combinatorial code of morphogenetic gradients and transcription factor networks (for review see Jessell, 2000). Many components of the transcriptional and signaling components necessary for proper motor neuron pattern formation have been well characterized. Recent evidence suggests that miRNAs also play important roles in regulating the balance between cross-repressive transcription factors within the neural tube. miR-196, miR-17-3p and miR-9 appear to provide boundary information within the developing spinal cord by refining transcription factor networks during motor neuron specification (Asli and Kessel, 2010; Bonev et al., 2011; Chen et al., 2011). Interestingly, the biological role of each of these miRNAs during neurogenesis differs spatially and temporally along the developing embryos' axis, suggesting that miRNAs can have diverse functions within neurons depending on the milieu of mRNAs they encounter. For instance, the combinatorial action of multiple miRNAs can result in stronger gene repression leading to greater changes within genetic networks (Wu et al., 2010). Therefore, regionally specific miRNAs could coordinate specific programs of neural development. Further studies integrating spatially and temporally expressed miRNAs within the nervous system may provide insights into the generation of neuronal diversity.

Despite different biological outputs, miRNAs both inside and outside of the nervous system have been consistently identified has key mediators of both feedforward and feedback loops. Here, the repressive activity of miRNAs can act both to activate or inhibit gene expression. The redundancy built in these systems is thought to provide robustness to genetic networks (Ebert and Sharp, 2012). Below, we review evidence demonstrating the importance of miRNAs in enforcing genetic programs through feedforward and feedback loops during cortical neuron development, one of the most characterized neural fate programs. 


\section{Feedback Inhibition During Cortical Neurogenesis}

miR-9, one of the most widely studied neuronal miRNAs participates in a wide variety of neuronal differentiation programs (Coolen et al., 2013; Kapsimali et al., 2007). It plays a vital role in the differentiation of neural progenitors into post-mitotic neurons by modulating a host of targets (reviewed in Coolen et al., 2013). Within the developing forebrain, the orphan nuclear receptor TLX maintains neural stems cells in a proliferative state through activation of Wnt/ $\beta$-catenin and recruitment of histone deacetylases that repress the loci of p21 and PTEN (Qu et al., 2010; Sun et al., 2007). Suppression of TLX expression in neural stem cells by miR-9 leads to decreased proliferation, premature differentiation, and migration toward the cortical plate (Zhao et al., 2009). It is thought that during normal development this repressive interaction regulates the differentiation of cortical progenitors. Premature differentiation is prevented at least in part, by the repression of miR-9 by TLX (Zhao et al., 2009). Others have also shown that processes mediated by miR-9 can be attributed to several targets within the cortical progenitor pool (Shibata et al., 2011). This negative feedback loop is further strengthened by additional miRNAs and targets of miR-9. For example, TLX expression is repressed during neurogenesis by let7b (Zhao et al., 2010). miR-137, also highly expressed in the brain, targets LSD1, a co-repressor that acts in conjunction with TLX to mediate transcriptional repression (Sun et al., 2011). This indicates that the effects of these miRNAs, when expressed together, may have a more dramatic phenotype than previously reported. The negative feedback loops present during cortical neurogenesis are depicted in Fig1. It is interesting to note that in each of these studies, overexpression of these miRNAs individually caused remarkably similar phenotypes and the expression of a single target often mitigated these effects. In addition, it is unknown if this regulatory relationship can be extended outside the cortical compartment. While miR-9 is expressed throughout the vertebrate nervous system (Lagos-Quintana et al., 2002), the pool of target mRNAs and co-repressive miRNAs could vary between neuronal populations. The ability of pan neuronal miRNAs to function differently within different neuronal populations remains an open question.

In the case of cortical neuron specification and differentiation, miRNAs clearly integrate into known genetic pathways, providing additional information to the developing nervous system. However, their relationship to one another and the network as a whole remains unclear. If miR-9, miR-137, and let7d have overlapping expression patterns, it is possible that they share common targets and their effect on cell fate is more pronounced than previously reported. Such synergy has been clearly demonstrated with the brain enriched miRNAs miR-9/9* and miR-124 (miR-9/9*-124) in chromatin regulation as described below.

\section{miRNAs and Epigenetic Regulation}

During development, ATP-dependent chromatin remodeling complexes acquire new activities by altering their subunit compositions (Ronan et al., 2013). Differentiation of neural progenitors into neurons is accompanied by a switch in the subunit composition of the mammalian SWI/SNF (BAF) chromatin remodeling complex. Specifically, subunits present in neural progenitors are exchanged with the neuron specific BAF45B/C, CREST, 
and BAF53b subunits (Lessard et al., 2007; Staahl et al., 2013; Wu et al., 2007). miR-9/9* and miR-124, regulate this switch by targeting the 3' UTR of BAF53a and prolonged expression of BAF53a in vivo represses BAF53b expression suggesting that miR-9/9*-124 expression initiates a feedforward loop that culminates in the swap of subunits within the BAF complex (Yoo et al., 2009). The onset of this regulatory cascade is instigated through a negative feedback loop between miR-9/9*-124 and the RE1 silencing transcription factor (REST/NRSF) complex (Conaco et al., 2006; Packer et al., 2008).

REST/NRSF was initially identified as a neuronal repressor that prevents the expression of neuronal genes outside the nervous system (Chong et al., 1995; Schoenherr and Anderson, 1995). This repressive activity is attained by recruiting other co-repressors such as co-REST, SCP1, MeCP2, and histone deacetylases (Andrés et al., 1999; Lunyak, 2002; Roopra et al., 2000; Yeo, 2005). As neural progenitors differentiate into post-mitotic neurons, REST/ NRSF-mediated repression is relieved upon the inhibition of REST/NRSF expression (Ballas et al., 2005). Interestingly, REST/NRSF and co-REST have been shown to be regulated by miR-9 and miR-9*, respectively (Packer et al., 2008). The sharp contrast in REST/NRSF expression between neuronal and non-neuronal cells is maintained through mutual repression between miR-9 and REST/NRSF. This negative feedback loop contributes to the neuronal specific expression of miR-9/9*-124 as all the active loci of miR-9/9* and miR-124 are occupied by REST/NRSF in non-neuronal cells (Conaco et al., 2006). In addition, SCP1, a component of the REST/NRSF silencing complex that facilitates neuronal silencing, was shown to be targeted by miR-124 (Visvanathan et al., 2007).

The loss of REST/NRSF-mediated repression and concomitant upregulation of neuron specific gene expression is also accompanied by neuron specific splicing events ( $\mathrm{Li}$ et al., 2007). Makayev et al., observed that when miR-124 was overexpressed in two neuroblastoma cell lines they adopted a neuron-like morphology and contained neuronspecific alternatively spliced transcripts (Makeyev et al., 2007). They showed that the downregulation of the splicing repressor PTBP1 by miR-124 leads to neuronal specific splicing events including the production of PTBP2, a neuron-specific splicing regulator that is normally excluded from non-neuronal cells by PTBP1 (Boutz et al., 2007). Here, the reciprocal expression of PTBP1 and PTBP2 is initiated by miR-124 creating both a feedforward and feedback loop. A summary of the miR-9/9*-124 dependent regulatory circuit is shown in Figure 2.

Negative feedback loops are continually being characterized between miRNAs and their repressors, and the sum of these feedback loops can have dramatic effects when the balance is sharply tipped in one direction. For instance, ectopic expression of miR-9/9*-124 directly converts human fibroblasts into post-mitotic neurons (Figure 3) (Yoo et al., 2011). While neither miRNA alone is capable of reprogramming the human fibroblasts, the neuronal conversion can be enhanced with the addition of neuronal transcription factors, revealing a synergy between multiple miRNAs and pro-neural transcription factors. The observation that miRNAs alone are capable of switching cell fate demonstrates their potency in regulating neuronal gene networks. Others have also taken advantage of manipulating the genetic circuit involved in neuronal specific splicing to achieve neuronal reprogramming (Xue et al., 2013). 


\section{Asymmetric Cell Division and Neuron Specific miRNA Activity}

One of the large outstanding questions in mammalian neurogenesis is how asymmetric division of neural stem cells is regulated. Recently Schwamborn et al, uncovered that TRIM32, a TRIM NHL protein, is asymmetrically inherited during neural progenitor division (Schwamborn et al., 2009). The daughter cell that does not receive TRIM32 remains a neural progenitor while the daughter inheriting the TRIM32 protein differentiates into a neuron. The mechanism behind this differentiation is due to two separate activities performed by TRIM32. As a ubiquitin ligase TRIM32 tags c-Myc for degradation. Repression of c-Myc leads to cell cycle exit and further participates in neural induction. Secondly, TRIM32 complexes with Ago1 leading to enhanced activity of several pro-neural miRNAs. One of these miRNAs, let7a, contributes to neural differentiation although not to the extent of TRIM32. Others have also shown let7a has both anti-proliferative effects and is upregulated during neurogenesis (Peng et al., 2008; Rybak et al., 2008). The effects of TRIM-32 on other pro-neural miRNAs remains unexplored.

\section{Conclusion}

Much like transcription factors, miRNAs can exist in feedback loops with their repressors or activators enabling binary switches and signal amplification, respectively. The cumulative effect of each regulatory node described thus far results in the vast array of highly specialized cells within the nervous system that connect and communicate in an even more complex manner. Our understanding of the development of specific types of neurons has been limited to the transcription factors necessary for the development of these populations. The advent of new technologies enables mechanistic studies focusing on the function of specific miRNAs during the development, and subsequent maintenance of neuronal subtypes. Further understanding of the genetic networks that connect each of these pathways within a single cell-type will greatly facilitate our understanding of neural development. To date, much progress has been made in understanding miRNAs and target interactions in neurogenesis. The results described here are a group of select studies that demonstrate both the importance of miRNA-dependent genetic networks and the need to connect this accumulated knowledge.

\section{References}

Andrés ME, Burger C, Peral-Rubio MJ, Battaglioli E, Anderson ME, Grimes J, Dallman J, Ballas N, Mandel G. CoREST: a functional corepressor required for regulation of neuralspecific gene expression. Proc. Natl. Acad. Sci. U.S.a. 1999; 96:9873-9878. [PubMed: 10449787]

Asli NS, Kessel M. Developmental Biology. Developmental Biology. 2010; 344:857-868. [PubMed: 20553899]

Ballas N, Grunseich C, Lu DD, Speh JC, Mandel G. REST and its corepressors mediate plasticity of neuronal gene chromatin throughout neurogenesis. Cell. 2005; 121:645-657. [PubMed: 15907476]

Bartel DP. MicroRNAs: target recognition and regulatory functions. Cell. 2009; 136:215-233. [PubMed: 19167326]

Bazzini AA, Lee MT, Giraldez AJ. Ribosome profiling shows that miR-430 reduces translation before causing mRNA decay in zebrafish. Science Signaling. 2012; 336:233-237. 
Bentwich I, Avniel A, Karov Y, Aharonov R, Gilad S, Barad O, Barzilai A, Einat P, Einav U, Meiri E, et al. Identification of hundreds of conserved and nonconserved human microRNAs. Nat. Genet. 2005; 37:766-770. [PubMed: 15965474]

Bernstein E, Kim SY, Carmell MA, Murchison EP, Alcorn H, Li MZ, Mills AA, Elledge SJ, Anderson KV, Hannon GJ. Dicer is essential for mouse development. Nat. Genet. 2003; 35:215-217. [PubMed: 14528307]

Bonev B, Pisco A, Papalopulu N. MicroRNA-9 Reveals Regional Diversity of Neural Progenitorsalong the Anterior-Posterior Axis. Dev. Cell. 2011; 20:19-32. [PubMed: 21238922]

Boudreau RL, Jiang P, Gilmore BL, Spengler RM, Tirabassi R, Nelson JA, Ross CA, Xing Y, Davidson BL. NeuroResource. Neuron. 2013:1-12.

Boutz PL, Stoilov P, Li Q, Lin CH, Chawla G, Ostrow K, Shiue L, Ares M, Black DL. A posttranscriptional regulatory switch in polypyrimidine tract-binding proteins reprograms alternative splicing in developing neurons. Genes \& Development. 2007; 21:1636-1652. [PubMed: 17606642]

Buckley BA, Burkhart KB, Gu SG, Spracklin G, Kershner A, Fritz H, Kimble J, Fire A, Kennedy S. A nuclear Argonaute promotes multigenerational epigenetic inheritance and germline immortality. Nature. 2012; 489:447-451. [PubMed: 22810588]

Cao X, Yeo G, Muotri AR, Kuwabara T. Noncoding RNAs in the mammalian central nervous system. Annu Rev .... 2006

Chen J-A, Huang Y-P, Mazzoni EO, Tan GC, Zavadil J, Wichterle H. Mir-17-3p ControlsSpinal Neural Progenitor Patterningby Regulating Olig2/Irx3 Cross-Repressive Loop. Neuron. 2011; 69:721-735. [PubMed: 21338882]

Chi SW, Hannon GJ, Darnell RB. An alternative mode of microRNA target recognition. Nat Struct Mol Biol. 2012; 19:321-327. [PubMed: 22343717]

Chi SW, Zang JB, Mele A, Darnell RB. Argonaute HITS-CLIP decodes microRNA|[ndash]|mRNA interaction maps. Nature. 2009; 460:479-486. [PubMed: 19536157]

Chong JA, Tapia-Ramirez J, Kim S, Toledo-Aral JJ, Zheng Y, Boutros MC, Altshuller YM, Frohman MA, Kraner SD, Mandel G. REST: A mammalian silencer protein that restricts sodium channel gene expression to neurons. Cell. 1995; 80:949-957. [PubMed: 7697725]

Cochella L, Hobert O. Diverse Functions of MicroRNAs in Nervous System Development. Current Topics in Developmental Biology, (Elsevier). 2012:115-143.

Conaco C, Otto S, Han JJ, Mandel G. Reciprocal actions of REST and a microRNA promote neuronal identity. Proc. Natl. Acad. Sci. U.S.a. 2006; 103:2422-2427. [PubMed: 16461918]

Coolen M, Katz S, Bally-Cuif L. miR-9: a versatile regulator of neurogenesis. Front Cell Neurosci. 2013; 7

De Pietri Tonelli D, Pulvers JN, Haffner C, Murchison EP, Hannon GJ, Huttner WB. miRNAs are essential for survival and differentiation of newborn neurons but not for expansion of neural progenitors during early neurogenesis in the mouse embryonic neocortex. Development. 2008; 135:3911-3921. [PubMed: 18997113]

Djuranovic S, Nahvi A, Green R. miRNA-Mediated Gene Silencing by Translational Repression Followed by mRNA Deadenylation and Decay. Science Signaling. 2012; 336:237-240.

Ebert MS, Sharp PA. Roles for MicroRNAs in Conferring Robustness to Biological Processes. Cell. 2012; 149:515-524. [PubMed: 22541426]

Götz M, Huttner WB. The cell biology of neurogenesis. Nature Publishing Group. 2005; 6:777-788.

Hafner M, Landthaler M, Burger L, Khorshid M, Hausser J, Berninger P, Rothballer A, Ascano M, Jungkamp A-C, Munschauer M, et al. Transcriptome-wide identification of RNA-binding protein and microRNA target sites by PAR-CLIP. Cell. 2010; 141:129-141. [PubMed: 20371350]

He M, Liu Y, Wang X, Zhang MQ, Hannon GJ, Huang ZJ. Cell-Type-Based Analysis of MicroRNA Profiles in the Mouse Brain. Neuron. 2012; 73:35-48. [PubMed: 22243745]

Helwak A, Kudla G, Dudnakova T, Tollervey D. Mapping the Human miRNA Interactome by CLASH Reveals Frequent Noncanonical Binding. Cell. 2013; 153:654-665. [PubMed: 23622248]

Hobert O, Carrera I, Stefanakis N. The molecular and gene regulatory signature of a neuron. Trends Neurosci. 2010; 33:435-445. [PubMed: 20663572] 
Hu HY, Guo S, Xi J, Yan Z, Fu N, Zhang X, Menzel C, Liang H, Yang H, Zhao M, et al. MicroRNA Expression and Regulation in Human, Chimpanzee, and Macaque Brains. PLoS Genet. 2011; 7:e1002327. [PubMed: 22022286]

Jeffries CD, Fried HM, Perkins DO. Nuclear and cytoplasmic localization of neural stem cell microRNAs. Rna. 2011; 17:675-686. [PubMed: 21363885]

Jessell TM. Neuronal specification in the spinal cord: inductive signals and transcriptional codes. Nat. Rev. Genet. 2000; 1:20-29. [PubMed: 11262869]

Kapsimali M, Kloosterman WP, de Bruijn E, Rosa F, Plasterk RH, Wilson SW. MicroRNAs show a wide diversity of expression profiles in the developing and mature central nervous system. Genome Biol. 2007; 8:R173. [PubMed: 17711588]

Kawase-Koga Y, Otaegi G, Sun T. Different timings of Dicer deletion affect neurogenesis and gliogenesis in the developing mouse central nervous system. Dev. Dyn. 2009; 238:2800-2812. [PubMed: 19806666]

Khudayberdiev SA, Zampa F, Rajman M, Schratt G. A comprehensive characterization of the nuclear microRNA repertoire of post-mitotic neurons. Front Mol Neurosci. 2013; 6:1-19.

Krol J, Loedige I, Filipowicz W. The widespread regulation of microRNA biogenesis, function and decay. Nat. Rev. Genet. 2010; 11:597-610. [PubMed: 20661255]

Lagos-Quintana M, Rauhut R, Yalcin A, Meyer J, Lendeckel W, Tuschl T. Identification of tissuespecific microRNAs from mouse. Curr. Biol. 2002; 12:735-739. [PubMed: 12007417]

Lee I, Ajay SS, Yook JI, Kim HS, Hong SH, Kim NH, Dhanasekaran SM, Chinnaiyan AM, Athey BD. New class of microRNA targets containing simultaneous 5“-UTR and 3-"UTR interaction sites. Genome Research. 2009; 19:1175-1183. [PubMed: 19336450]

Lee Y, Jeon K, Lee JT, Kim S, Kim VN. MicroRNA maturation: stepwise processing and subcellular localization. Embo J. 2002; 21:4663-4670. [PubMed: 12198168]

Lessard J, Wu JI, Ranish JA, Wan M, Winslow MM, Staahl BT, Wu H, Aebersold R, Graef IA, Crabtree GR. An Essential Switch in Subunit Composition of a Chromatin Remodeling Complex during Neural Development. Neuron. 2007; 55:201-215. [PubMed: 17640523]

Li Q, Lee J-A, Black DL. Neuronal regulation of alternative pre-mRNA splicing. Nat. Rev. Neurosci. 2007; 8:819-831. [PubMed: 17895907]

Liu C-G, Calin GA, Meloon B, Gamliel N, Sevignani C, Ferracin M, Dumitru CD, Shimizu M, Zupo $\mathrm{S}$, Dono M, et al. An oligonucleotide microchip for genome-wide microRNA profiling in human and mouse tissues. Proc. Natl. Acad. Sci. U.S.a. 2004; 101:9740-9744. [PubMed: 15210942]

Lukiw WJ. Evolution and complexity of micro RNA in the human brain. 2012:1-3.

Lunyak VV. Corepressor-Dependent Silencing of Chromosomal Regions Encoding Neuronal Genes. Science. 2002; 298:1747-1752. [PubMed: 12399542]

Lytle JR, Yario TA, Steitz JA. Target mRNAs are repressed as efficiently by microRNA-binding sites in the 5"UTR as in the 3" UTR. Proc. Natl. Acad. Sci. U.S.a. 2007; 104:9667-9672. [PubMed: 17535905]

Makeyev EV, Zhang J, Carrasco MA, Maniatis T. The MicroRNA miR-124 Promotes Neuronal Differentiation by Triggering Brain-Specific Alternative Pre-mRNA Splicing. Molecular Cell. 2007; 27:435-448. [PubMed: 17679093]

Morris SA, Daley GQ. A blueprint for engineering cell fate: current technologies to reprogram cell identity. Cell Res. 2013; 23:33-48. [PubMed: 23277278]

Packer AN, Xing Y, Harper SQ, Jones L, Davidson BL. The Bifunctional microRNA miR-9/miR-9* Regulates REST and CoREST and Is Downregulated in Huntington's Disease. Journal of Neuroscience. 2008; 28:14341-14346. [PubMed: 19118166]

Pasquinelli AE. Non-coding RNA: MicroRNAs and their targets: recognition, regulation and an emerging reciprocal relationship. Nat. Rev. Genet. 2012; 13:271-282. [PubMed: 22411466]

Pauli A, Rinn JL, Schier AF. Non-coding RNAs as regulators of embryogenesis. Nat. Rev. Genet. 2011; 12:136-149. [PubMed: 21245830]

Peng Y, Laser J, Shi G, Mittal K, Melamed J, Lee P, Wei J-J. Antiproliferative effects by Let-7 repression of high-mobility group A2 in uterine leiomyoma. Mol. Cancer Res. 2008; 6:663-673. [PubMed: 18403645] 
Peter ME. Targeting of mRNAs by multiple miRNAs: the next step. Oncogene. 2010; 29:2161-2164. [PubMed: 20190803]

Qu Q, Sun G, Li W, Yang S, Ye P, Zhao C, Yu RT, Gage FH, Evans RM, Shi Y. Orphan nuclear receptor TLX activates Wnt/beta-catenin signalling to stimulate neural stem cell proliferation and self-renewal. Nat Cell Biol. 2010; 12 31-40-suppp1-9.

Ronan JL, Wu W, Crabtree GR. From neural development to cognition: unexpected roles for chromatin. Nat. Rev. Genet. 2013; 14:347-359. [PubMed: 23568486]

Roopra A, Sharling L, Wood IC, Briggs T, Bachfischer U, Paquette AJ, Buckley NJ. Transcriptional Repression by Neuron-Restrictive Silencer Factor Is Mediated via the Sin3-Histone Deacetylase Complex. Molecular and Cellular Biology. 2000; 20:2147-2157. [PubMed: 10688661]

Rybak A, Fuchs H, Smirnova L, Brandt C, Pohl EE, Nitsch R, Wulczyn FG. A feedback loop comprising lin-28 and let-7 controls pre-let-7 maturation during neural stem-cell commitment. Nat Cell Biol. 2008; 10:987-993. [PubMed: 18604195]

Schoenherr CJ, Anderson DJ. The neuron-restrictive silencer factor (NRSF): a coordinate repressor of multiple neuron-specific genes. Science. 1995; 267:1360-1363. [PubMed: 7871435]

Schwamborn JC, Berezikov E, Knoblich JA. The TRIM-NHL protein TRIM32 activates microRNAs and prevents self-renewal in mouse neural progenitors. Cell. 2009; 136:913-925. [PubMed: 19269368]

Sempere LF, Freemantle S, Pitha-Rowe I, Moss E, Dmitrovsky E, Ambros V. Expression profiling of mammalian microRNAs uncovers a subset of brain-expressed microRNAs with possible roles in murine and human neuronal differentiation. Genome Biol. 2004; 5:R13. [PubMed: 15003116]

Shibata M, Nakao H, Kiyonari H, Abe T, Aizawa S. MicroRNA-9 Regulates Neurogenesis in Mouse Telencephalon by Targeting Multiple Transcription Factors. Journal of Neuroscience. 2011; 31:3407-3422. [PubMed: 21368052]

Staahl BT, Tang J, Wu W, Sun A, Gitler AD, Yoo AS, Crabtree GR. Kinetic Analysis of npBAF to nBAF Switching Reveals Exchange of SS18 with CREST and Integration with Neural Developmental Pathways. Journal of Neuroscience. 2013; 33:10348-10361. [PubMed: 23785148]

Stern CD. Neural induction: old problem, new findings, yet more questions. Development. 2005; 132:2007-2021. [PubMed: 15829523]

Sun AX, Crabtree GR, Yoo AS. MicroRNAs: regulators of neuronal fate. Current Opinion in Cell Biology. 2013:1-7.

Sun G, Ruth TY, Evans RM, Shi Y. Orphan nuclear receptor TLX recruits histone deacetylases to repress transcription and regulate neural stem cell proliferation. Proc. Natl. Acad. Sci. U.S.a. 2007; 104:15282-15287. [PubMed: 17873065]

Sun G, Ye P, Murai K, Lang M-F, Li S, Zhang H, Li W, Fu C, Yin J, Wang A, et al. miR-137 forms a regulatory loop with nuclear receptor TLX and LSD1 in neural stem cells. Nature Communications. 2011; 2:529.

Ule J, Jensen K, Mele A, Darnell RB. CLIP: a method for identifying protein-RNA interaction sites in living cells. Methods. 2005; 37:376-386. [PubMed: 16314267]

Visvanathan J, Lee S, Lee B, Lee JW, Lee SK. The microRNA miR-124 antagonizes the anti-neural REST/SCP1 pathway during embryonic CNS development. Genes \& Development. 2007; $21: 744$ 749. [PubMed: 17403776]

Volvert M-L, Rogister F, Moonen G, Malgrange B, Nguyen L. MicroRNAs tune cerebral cortical neurogenesis. Cell Death and Differentiation. 2012; 19:1573-1581. [PubMed: 22858543]

Wu JI, Lessard J, Olave IA, Qiu Z, Ghosh A, Graef IA, Crabtree GR. Regulation of Dendritic Development by Neuron-Specific Chromatin Remodeling Complexes. Neuron. 2007; 56:94-108. [PubMed: 17920018]

Wu S, Huang S, Ding J, Zhao Y, Liang L, Liu T, Zhan R, He X. Multiple microRNAs modulate p21Cip1/Waf1 expression by directly targeting its $3^{\prime}$ untranslated region. Oncogene. 2010; 29:2302-2308. [PubMed: 20190813]

Xue Y, Ouyang K, Huang J, Zhou Y, Ouyang H, Li H, Wang G, Wu Q, Wei C, Bi Y, et al. Direct Conversion of Fibroblasts to Neurons by Reprogramming PTB-Regulated MicroRNA Circuits. Cell. 2013; 152:82-96. [PubMed: 23313552] 
Yeo M. Small CTD Phosphatases Function in Silencing Neuronal Gene Expression. Science. 2005; 307:596-600. [PubMed: 15681389]

Yoo AS, Staahl BT, Chen L, Crabtree GR. MicroRNA-mediated switching of chromatin-remodelling complexes in neural development. Nature. 2009; 460:642-646. [PubMed: 19561591]

Yoo AS, Sun AX, Li L, Shcheglovitov A, Portmann T, Li Y, Lee-Messer C, Dolmetsch RE, Tsien RW, Crabtree GR. MicroRNA-mediated conversion of human fibroblasts to neurons. Nature. 2011; 476:228-231. [PubMed: 21753754]

Zhao C, Sun G, Li S, Shi Y. A feedback regulatory loop involving microRNA-9 and nuclear receptor TLX in neural stem cell fate determination. Nat Struct Mol Biol. 2009; 16:365-371. [PubMed: 19330006]

Zhao C, Sun G, Li S, Lang M-F, Yang S, Li W, Shi Y. MicroRNA let-7b regulates neural stem cell proliferation and differentiation by targeting nuclear receptor TLX signaling. Proc. Natl. Acad. Sci. U.S.a. 2010; 107:1876-1881. [PubMed: 20133835]

Ørom UA, Nielsen FC, Lund AH. MicroRNA-10a Binds the 5'UTR of Ribosomal Protein mRNAs and Enhances Their Translation. Molecular Cell. 2008; 30:460-471. [PubMed: 18498749] 

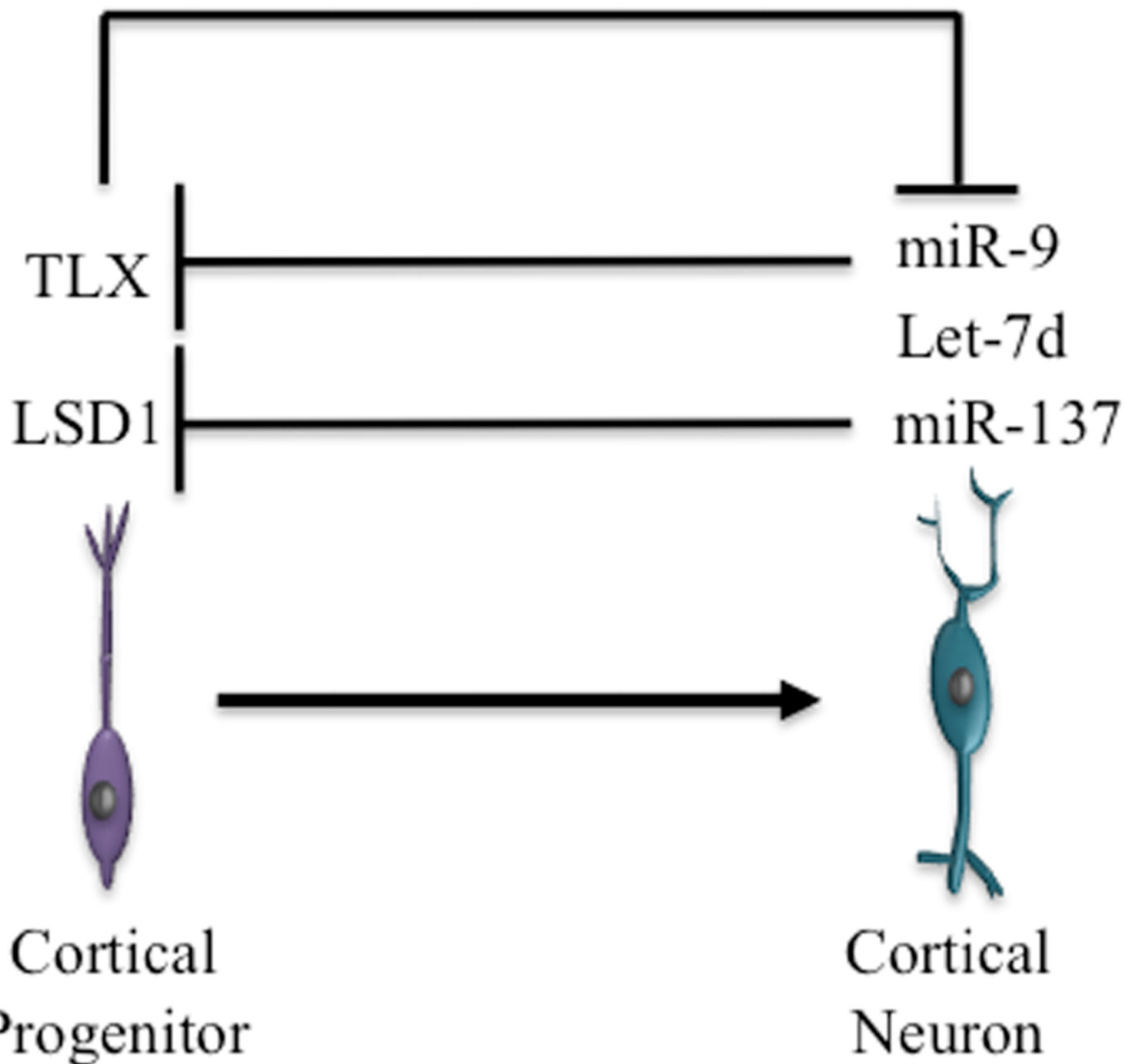

Fig. 1.

miRNA-dependent negative feedback loops in cortical neurogenesis. As cortical progenitors differentiate into cortical neurons the expression of miR-9 and miR-137 is induced leading to the direct repression of the orphan nuclear receptor TLX. The expression of miR-9 and miR-137 is normally repressed in cortical progenitors by TLX. This negative feedback loop is further reinforced by the repression of LSD1, a corepressor that acts in concert with TLX, by miR-137. 


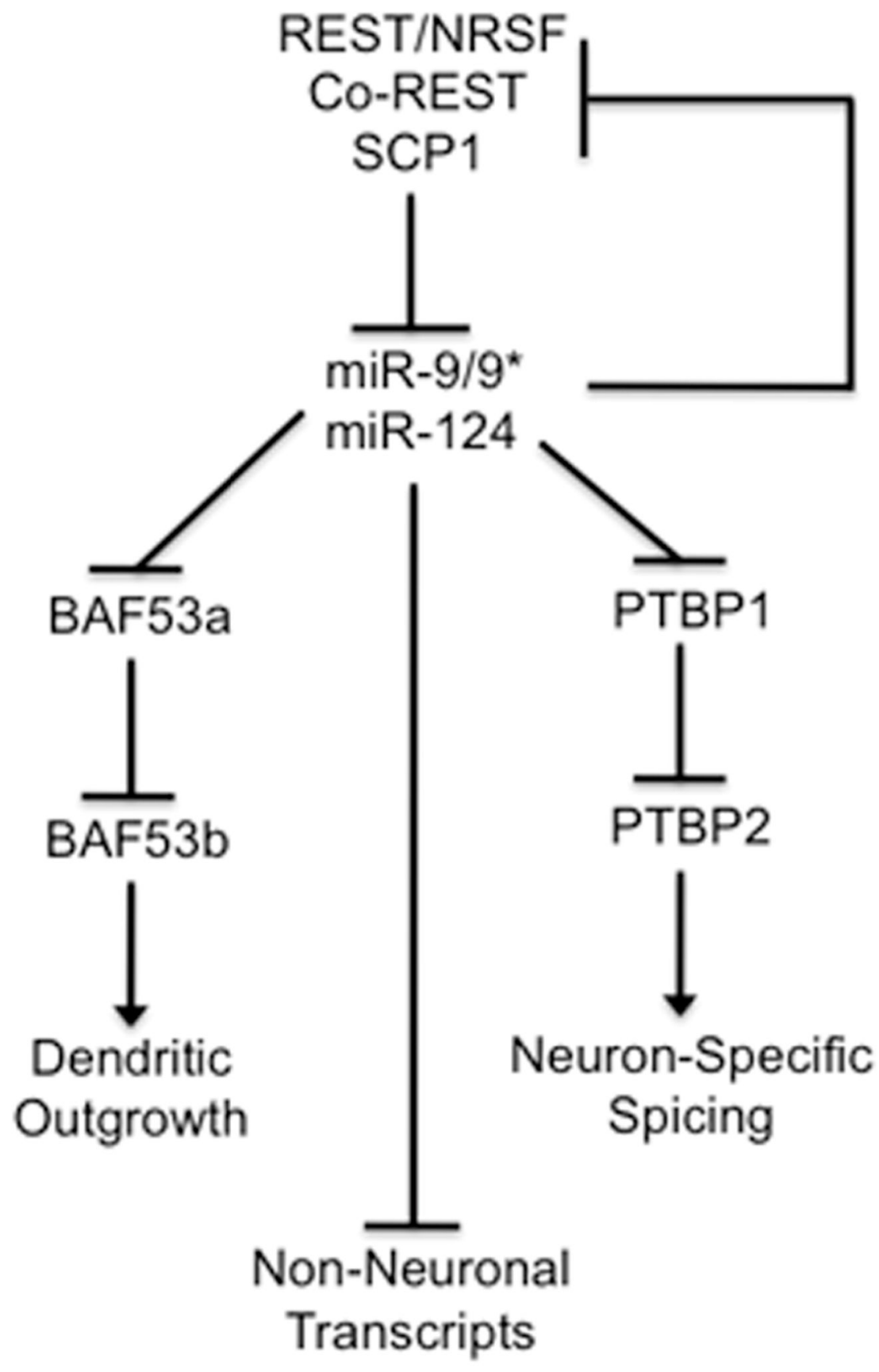

Neuron

Fig. 2.

miR-9/9*, miR-124 and REST coordinate neurogenesis through multiple positive and negative feedback loops. REST silences many neuronal genes including miR-9/9* and miR-124. At the onset of neural differentiation, miR-9/9* and miR-124 are upregulated leading to the repression of their targets, REST, BAF53a and PTBP1. REST, co-REST, and SCP1 repress miR-9/9* and miR-124 which creates a feedback loop allowing for distinct, reciprocal expression patterns. BAF53a normally inhibits BAF53b, the relief of this repression by miR-9/9* and miR-124 enables BAF53b expression and formation of neuron 
specific BAF chromatin remodeling complex which is important for proper dendritic outgrowth. This feedforward loop is distinct from PTBP1's repression by miR-124. Here, neuron specific splicing is accomplished by repression of one splicing repressor, PTBP1, which directly represses the expression of another splicing regulator PTBP2. During neurogenesis, the expression of miR-9/9* and miR-124 that are activated at least in part by dismissal of REST binding leads to a cascade of genetic events that strongly re-enforces the neurogenic program. 


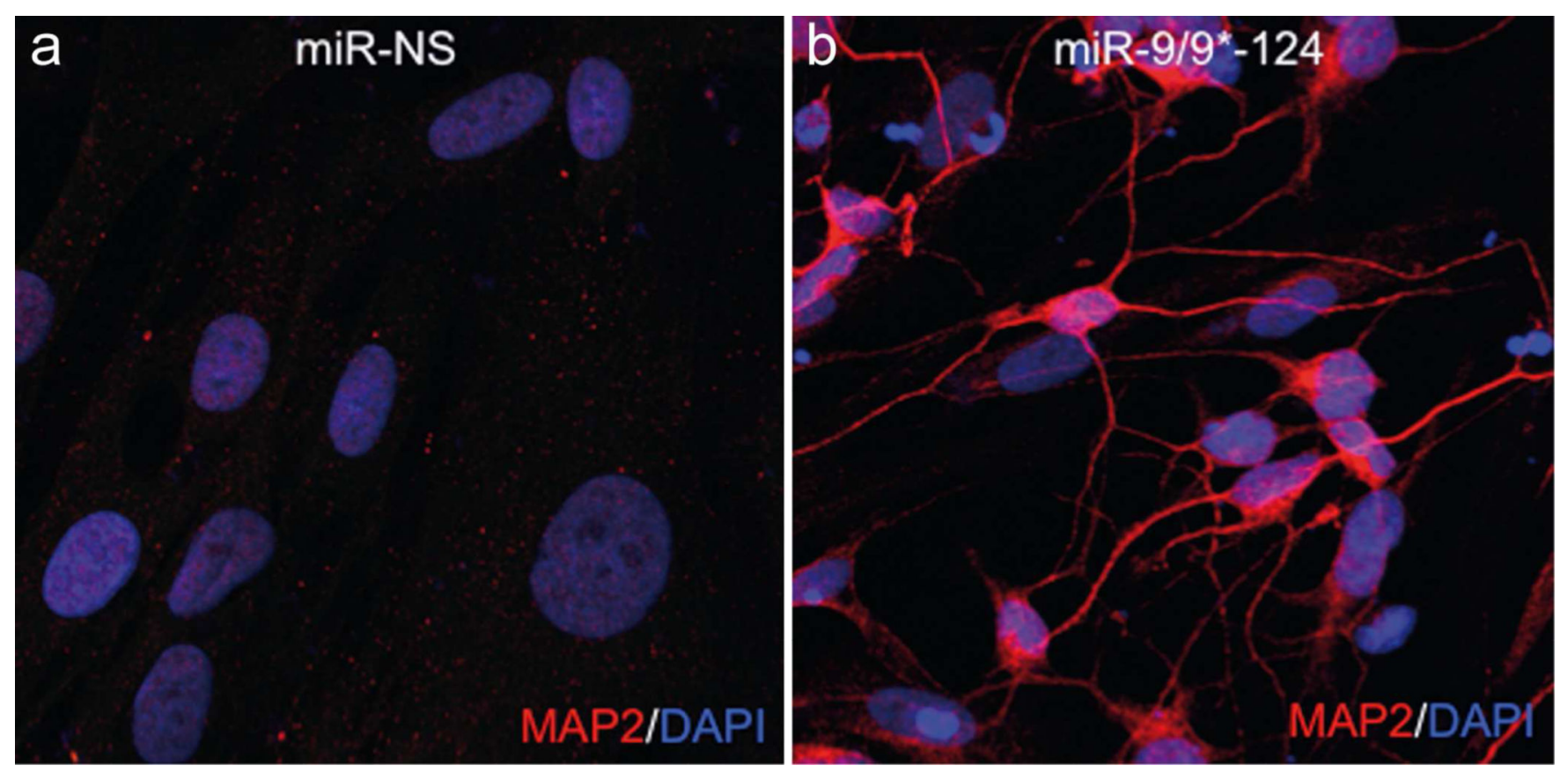

Fig. 3.

Neuronal conversion of primary human dermal fibroblasts mediated by miR-9/9*-124.

Pictures depict (A) human neonatal fibroblasts and (B) converted cells immunostained with a pan-neuronal marker, MAP2 (adapted from Yoo et al., 2011). 